\title{
Does over-the-counter nicotine replacement therapy improve smokers' life expectancy?
}

\author{
William F Lawrence, Stevens S Smith, Timothy B Baker, Michael C Fiore
}

\begin{abstract}
Objective-To determine the public health benefits of making nicotine replacement therapy available without prescription, in terms of number of quitters and life expectancy.

Design-A decision-analytic model was developed to compare the policy of over-the-counter (OTC) availability of nicotine replacement therapy with that of prescription $(\mathrm{R})$ availability for the adult smoking population in the United States. Main outcome measures-Long-term (six-month) quit rates, life expectancy, and smoking attributable mortality (SAM) rates.

Results-OTC availability of nicotine replacement therapy would result in 91151 additional successful quitters over a six-month period, and a cumulative total of approximately 1.7 million additional quitters over 25 years. Allcause SAM would decrease by 348 deaths per year and 2940 deaths per year at six months and five years, respectively. Relative to $\mathrm{P}$ nicotine replacement therapy availability, OTC availability would result in an average gain in life expectancy across the entire adult smoking population of 0.196 years per smoker. In sensitivity analyses, the benefits of OTC availability were evident across a wide range of changes in baseline parameters.
\end{abstract}

Conclusions-Compared with R availability of nicotine replacement therapy, OTC availability would result in more successful quitters, fewer smoking-attributable deaths, and increased life expectancy for current smokers.

(Tobacco Control 1998;7:364-368)

Keywords: smoking cessation, nicotine replacement therapy, over-the-counter sales, decision analysis

\section{Introduction}

Smoking cessation and prevention strategies hold tremendous potential to improve public health. ${ }^{1}$ Smoking-attributable mortality is now estimated at more than 400000 deaths per year and the health benefits of quitting at any age have been well documented. ${ }^{2}$ Although over $70 \%$ of smokers would like to quit smoking, ${ }^{3}$ less than $5 \%$ of self-quitters successfully stop smoking for six months or more, ${ }^{4}$ a figure considerably lower than the $10-30 \%$ quit rates produced by smoking cessation programmes using prescription $(\mathrm{R})$ nicotine replacement products (transdermal patches or polacrilex gum).$^{5-7}$ Although smoking cessation programmes are more efficacious than self-quitting, considerable evidence suggests that most smokers are reluctant to participate in cessation programmes. ${ }^{8-10}$ This suggests that making nicotine replacement products available outside formal cessation programmes may increase smoking cessation rates among American smokers. One strategy to make nicotine replacement products more available to self-quitters is to make them available over the counter (OTC). ${ }^{11} 12$

In July 1996, the FDA first approved over-the-counter sales of one brand of nicotine patch. ${ }^{13}$ The patches appear to be a popular cessation aid; by the end of 1996, one brand of OTC nicotine patch, Nicoderm CQ, had sold over 3.2 million units (unpublished data, SmithKline Beecham, Inc.). Use of nicotine replacement therapy has been estimated to increase by over $150 \%$ since nicotine patches and nicotine gum have become available without prescription. ${ }^{14}$ An accurate estimate of the potential public health benefits of the policy of making nicotine replacement available without prescription depends upon formal analysis that models the anticipated benefit based upon specific, empirically derived assumptions. The current study used decision-analytic techniques to compare the public health impact of prescription with over-the-counter nicotine replacement therapy availability. The analyses used data on the estimated percentage of American smokers who would quit successfully per year, and on estimated reductions in smoking-attributable mortality, derived from sources available before nicotine replacement was available OTC in the United States, or from post-marketing surveillance after nicotine replacement was available without prescription.

\section{Methods}

We constructed a simulation model ${ }^{15}$ using a computer spreadsheet (Microsoft Excel for Windows version 5.0, Microsoft Corporation, Redmond, Washington) to compare the public health impact of making nicotine replacement therapy (NRT) by transdermal patch or by nicotine polacrilex gum available over the counter (OTC scenario) with the practice of prescription-only availability ( $\mathrm{P}$ scenario). We used data from non-prescription availability Nicoderm patch studies conducted by Alza Corporation as proxy for over-the-counter nicotine replacement in general, due to the availability of over-the-counter data for this particular product. Outcomes determined for 
Table 1 Model parameters

\begin{tabular}{|c|c|c|}
\hline Parameter & Value* & Sources \\
\hline \multicolumn{3}{|l|}{ OTC scenario } \\
\hline Probability of using NRT if attempting to quit & 0.35 & 8,14 \\
\hline Probability of quitting six months using NRT $†$ & 0.106 & 19 \\
\hline \multicolumn{3}{|l|}{ R Scenario } \\
\hline Probability of using NRT if attempting to quit & 0.14 & $8 \ddagger$ \\
\hline Probability of quitting six months using NRT $†$ & 0.106 & 19 \\
\hline \multicolumn{3}{|l|}{ Both scenarios } \\
\hline Probability of attempting to quit by any method & 0.31 & $17 \S$ \\
\hline attempting without NRT $\dagger$ & 0.049 & 4,24 \\
\hline \multicolumn{3}{|l|}{ Markov models } \\
\hline $\begin{array}{l}\text { One-year probability of relapse for quitters in } \\
\text { first two years }\end{array}$ & 0.11 & 29 \\
\hline $\begin{array}{l}\text { One-year probability of relapse for long-term } \\
\text { quitters }\end{array}$ & 0.024 & 29 \\
\hline $\begin{array}{l}\text { Relative risk of death, current smoker to former } \\
\text { smoker (age 18-29 years) }\end{array}$ & 1.0 & $\star \star$ \\
\hline $\begin{array}{l}\text { Relative risk of death for current smoker to } \\
\text { former smoker (age } \geqslant 30 \text { years) }\end{array}$ & $\begin{array}{l}\text { Age and sex dependent } \\
\text { (range: } 1.2-2.5 \text { ) }\end{array}$ & $1,17,23+\dagger$ \\
\hline One-year probability of death, former smoker & $\begin{array}{l}\text { Age and sex dependent } \\
\text { (range: } 0.0051-0.18 \text { ) }\end{array}$ & 16 \\
\hline
\end{tabular}

OTC $=$ over the counter; NRT $=$ nicotine replacement therapy.

*Values for table 1 are presented as the weighted average of values across age and sex strata.

†Based on self-reported continuous quit rates in OTC setting; see text.

$\ddagger$ Based on all reported NRT use (patch and gum) from Pierce et al. [8]

$\S$ Based on the 1992 National Health Interview Survey data from the National Center for Health Statistics on CD-ROM. These estimates were computed by Dr SS Smith, who is solely

responsible for the accuracy and appropriateness of the calculations.

|Estimates were based on two stage DEALE transformations[14] to estimate yearly relapse transition probabilities for short-term (1-2 year) and long-term quitters based on National transition probabilities for short-term (1-2 year)

$\star \star$ No data were available for this age group, so we used a conservative assumption that the mortality was not increased in current smokers relative to former for those less than 30 years old.

††Estimates were derived from the Cancer Prevention Study II (CPS-II), using the above sources, as well as unpublished CPS-II data provided by MJ Thun (personal communication). Data are stratified by age and sex, but are independent of duration of abstinence for former smokers.

both the OTC and $\mathrm{P}$ scenarios included: (a) the total number of smokers who quit at six months; (b) overall smoking-attributable mortality; and (c) life expectancy of an average smoker using state-transition (Markov) modelling.

\section{DATA SOURCES}

Modelling required estimates derived from diverse sources. A MEDLINE literature search was conducted for relevant literature on model parameters. Whenever possible, effectiveness data was preferentially chosen over efficacy data. Population estimates were based on 1990 census data. ${ }^{16}$ In addition, several national sur-

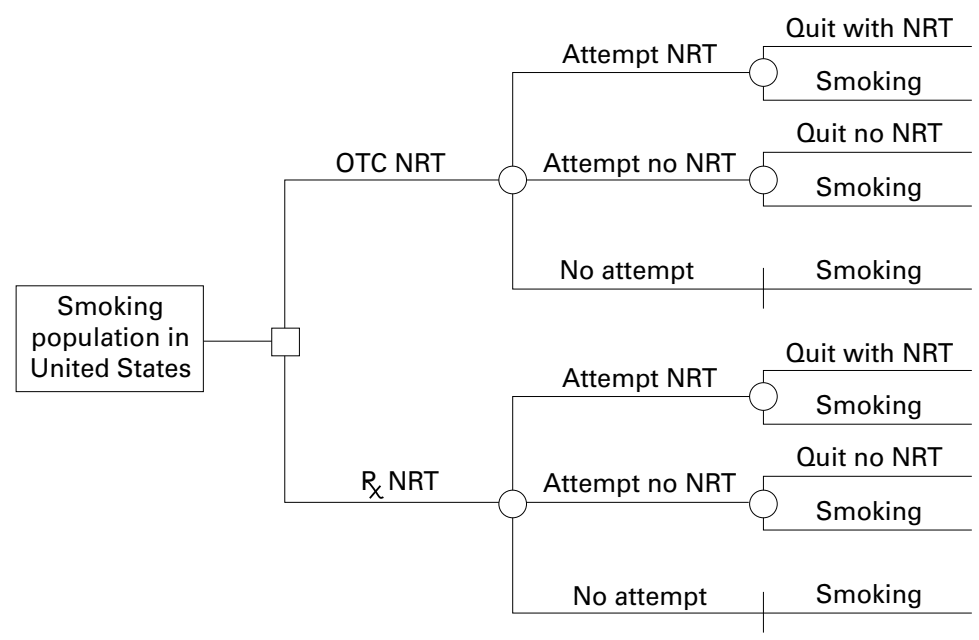

Figure 1 Decision tree for determining the public health benefits of the two scenarios of availability of nicotine replacement therapy. Public health benefits shown in the tree include the number of quit attempts and the number of long-term (six-month) quits. NRT = nicotine replacement therapy, OTC = over the counter, $\mathrm{R}=$ prescription. veys were used to provide population-based estimates, including the 1990 and 1992 National Health Interview Surveys, ${ }^{17} 18$ (NHIS) to provide estimates of smoking prevalence and smoking cessation attempts, and the National Health and Nutrition Examination Survey-I (NHANES-I) and the NHANES Epidemiologic Followup Survey ${ }^{2}$ to provide the probability of smoking relapse.

Estimates of the rate of use of nicotine replacement in the OTC scenario were based on marketing surveillance of nicotine replacement therapy use, performed by Shiffman and colleagues. ${ }^{14}$ These investigators determined the ratio of use of nicotine products for non-prescription availability compared with prescription availability. We used this ratio multiplied by our estimates for prescription use of nicotine replacement therapy to calculate the rates of use in the overthe-counter setting.

Smoking cessation rates for NRT quitters under both scenarios were derived from a prospective trial of simulated non-prescription nicotine patch use. ${ }^{19}$ As noted, we use nicotine patch data as a proxy for nicotine replacement therapy in general, due to the availability of the data on over-the-counter use for this form of replacement. A prospective cohort study was conducted using 2367 participants recruited from public locations such as shopping malls; participants purchased patches at estimated retail price, and were followed up to determine quit rates. Participants lost to follow up in this study were considered to have relapsed. We assume for this analysis that the six-month quit rates for smokers using nicotine replacement was equivalent in the OTC and $\mathrm{R}$ scenarios. Post-marketing surveillance using retrospective cohort data on prescription nicotine patch use $^{19}$ suggests that the six-month quit rate may actually be lower in the prescription setting. Thus, this assumption is a conservative one which will bias the analysis in favour of the prescription scenario by underestimating the over-the-counter public health benefit. We examine changes in this assumption in sensitivity analysis.

Whenever possible, age-specific and sexspecific data were used in the model. All quit rates are based upon self-reported continuous quit rates which were the most consistently available data. Table 1 provides a summary of parameters used for the baseline case for the model. (Parameter estimates stratified by age and sex from these studies are available in a technical report available on request from the authors.)

THE DECISION MODEL

A decision tree was constructed (figure 1) to estimate the number of current smokers who would quit long-term (six months) in the OTC and $\mathrm{P}$ scenarios for each age and sex stratum. In both scenarios, a smoker has a chance of making a quit attempt using nicotine replacement therapy, a chance of making a quit attempt without nicotine replacement, and a chance of not making a quit attempt. We assume for the baseline analysis that the total 
Table 2 Baseline results

\begin{tabular}{|c|c|c|}
\hline & R Scenario* & OTC Scenariot \\
\hline Number of adult smokers in the United States & 47002476 & 47002476 \\
\hline Number willing to try NRT per year & 1014630 & 2556867 \\
\hline Willing to try NRT per year (\%) & 2.2 & 5.4 \\
\hline Quit rate of smokers using NRT at six months (\%) & 10.8 & 10.8 \\
\hline Number of quits using NRT at six months & 109685 & 276405 \\
\hline Gain in number of quits for OTC scenario at six months & NA & 91151 \\
\hline Total number of quits at six months & 420330 & 511480 \\
\hline Life expectancy of average smoker (years) & 34.211 & 34.407 \\
\hline Gain in life expectancy for average smoker (years) & NA & 0.196 \\
\hline $\begin{array}{l}\text { Smoking-attributable mortality rate (based on six-month } \\
\text { data) (deaths per year) }\end{array}$ & 412617 & 412269 \\
\hline $\begin{array}{l}\text { Reduction in smoking-attributable mortality rate } \\
\text { (based on six-month data) (deaths per year) }\end{array}$ & NA & $348(0.1 \%)$ \\
\hline $\begin{array}{l}\text { Reduction in smoking-attributable mortality rate for OTC } \\
\text { scenario (based on five-year data) (deaths per year) }\end{array}$ & NA & $2940(0.7 \%)$ \\
\hline
\end{tabular}

*Nicotine replacement therapy (NRT) available only by prescription.

$\dagger$ Nicotine replacement therapy available over the counter (OTC).

$\mathrm{NA}=$ not applicable. stratified by age and sex, ${ }^{18}{ }^{21}$ however, data were not available to calculate this parameter for duration of cessation, so rates are independent of duration of abstinence for former smokers.

For each age and sex stratum, the initial distribution of cohort members across the states was determined by the outcome of the decision tree for that stratum. The model calculated life expectancy until the surviving members of the cohort reached age 100. Transition probabilities for the Markov models were age and sex dependent.

\section{Results}

BASELINE RESULTS

Major outcomes of the analysis are shown in table 2. Key findings are that making nicotine therapy available over the counter would result in approximately 1.1 million additional smokers attempting to quit using nicotine replacement therapy in the first six months, and an estimated 91151 additional smokers would have quit at the end of six months. The number of additional quitters from the current cohort of smokers would continue to increase over time to a maximum of 1.7 million additional quitters at 25 years in the OTC scenario compared with the $\mathrm{P}$ scenario (figure 2 ).

Reclassifying nicotine therapy as nonprescription would also have a positive impact on life expectancy. Across the total cohort of more than 47 million smokers (including continuing smokers and eventual quitters), the average smoker could be expected to live 0.20 years (2.4 months) longer in the over-thecounter scenario than in the prescription scenario (table 2). The impact of permanently quitting smokers on gain in life expectancy on successful quitters is presented in table 3. On average, each of these new quitters will gain an average of 4.4 years of life compared with smokers who never quit. Thus, the average gain in life expectancy represents a large life expectancy gain that accrues to the small percentage of smokers who would quit in the non-prescription availability setting but not in the prescription setting.

Based on the proportion of quitters at six months in the OTC scenario compared with that in the $\mathrm{R}$ scenario, we estimated a reduction in the all-cause, smokingattributable mortality rate of 348 deaths per year. At five years, our model predicts a decrease in the all-cause, smoking-attributable mortality rate of 2940 deaths per year for the over-the-counter scenario, due to the increased

Table 3 Gain in life expectancy* for smokers who successfully quit smoking

\begin{tabular}{llll}
\hline Age & Men & Women & Total \\
\hline $18-24$ & 6.30 & 4.01 & 5.28 \\
$25-44$ & 5.85 & 3.78 & 4.92 \\
$45-64$ & 4.26 & 3.43 & 3.86 \\
$\geqslant 65$ & 1.91 & 1.33 & 1.59 \\
Total & 5.22 & 3.47 & 4.41 \\
\hline
\end{tabular}

${ }^{\star}$ Gain in life expectancy (years) for individual smokers who successfully and permanently quit smoking today, compared successfully and permanently quit smoking today, compared
with smokers who continue to smoke for the rest of their lives. with smokers who continue to smoke for the rest of their
Totals represent average life expectancy weighted by the Totals represent average life expectancy weighted
number of people in each age and sex stratum. 
Table 4 Sensitivity analyses

\begin{tabular}{|c|c|c|}
\hline Parameter* & $\begin{array}{l}\text { Gain in number of quits at six } \\
\text { months (OTC scenario) }\end{array}$ & $\begin{array}{l}\text { Gain in life expectancyt (OTC } \\
\text { scenario) }\end{array}$ \\
\hline Baseline & 91151 & 0.196 \\
\hline \multicolumn{3}{|c|}{ Change in probability of attempting to quit by any method (baseline average $=0.31) \ddagger$} \\
\hline $0.75 \star$ baseline (average $=0.23$ ) & 68363 & 0.163 \\
\hline $1.25 \star$ baseline (average $=0.39)$ & 113939 & 0.222 \\
\hline \multicolumn{2}{|l|}{ Two quit attempts per year for those attempting to quit by } & 0.266 \\
\hline \multicolumn{3}{|c|}{ Relative chance of quit attempt by any method, OTC to $\mathrm{R}$ (baseline 1 to 1 ): } \\
\hline 0.9 to 1 & 40003 & 0.108 \\
\hline 1.1 to 1 & 142299 & 0.280 \\
\hline 1.3 to 1 & 244595 & 0.437 \\
\hline Threshold value $\$: 0.79$ to 1 & & \\
\hline \multicolumn{3}{|c|}{ Probability of using NRT should a quit attempt be made (both scenarios; baseline average $=0.14 \mathrm{R}, 0.36$ OTC) $\ddagger$} \\
\hline $0.5 *$ baseline (average $=0.07 \mathrm{R}, 0.18 \mathrm{OTC})$ & 45576 & 0.104 \\
\hline $0.75 \star$ baseline (average $=0.11 \mathrm{R}, 0.27 \mathrm{OTC})$ & 68363 & 0.152 \\
\hline $1.25 \star$ baseline (average $=0.18 \mathrm{R}, 0.45 \mathrm{OTC}$ ) & 113939 & 0.238 \\
\hline Threshold value $₫: 0$ & & \\
\hline \multicolumn{3}{|c|}{$\begin{array}{l}\text { Relative chance of using NRT for those quitting in OTC scenario compared with chance of using NPT in R scenario (baseline } \\
\text { average }=2.52 \text { to } 1) \ddagger\end{array}$} \\
\hline $0.5 \star$ baseline (average $=1.26$ to 1$)$ & 15592 & 0.035 \\
\hline 0.8 *baseline (average $=2.02$ to 1$)$ & 60927 & 0.133 \\
\hline $1.2 \star$ baseline $($ average $=3.02$ to 1$)$ & 121375 & 0.257 \\
\hline Threshold value $§: 0.40 ;{ }^{\star}$ baseline (average $=1$ to 1 ) & & \\
\hline \multicolumn{3}{|c|}{$\begin{array}{l}\text { Probability of a successful quit at six months for those attempting with NRT in the } \mathrm{R} \text { scenario (OTC scenario probabilities held } \\
\text { constant; baseline average }=0.106) \ddagger\end{array}$} \\
\hline $1.25 \star$ baseline (average $=133$ ) & 63730 & 0.137 \\
\hline $1.5 \star$ baseline (average $=0.159)$ & 36309 & 0.080 \\
\hline $2.0 \star$ baseline (average $=0.212$ ) & $(18534)$ & $(0.029)$ \\
\hline Threshold value $§: 1.86 ;{ }^{\star}$ baseline $($ average $=0.197)$ & & \\
\hline \multicolumn{3}{|c|}{$\begin{array}{l}\text { Probability of a successful quit at six months for those attempting with NRT in the OTC scenario (R scenario probabilities held } \\
\text { constant; baseline average }=0.106) \ddagger\end{array}$} \\
\hline $0.5 \star$ baseline $($ average $=0.053)$ & $(47052)$ & $(0.096)$ \\
\hline $0.75 \star$ baseline $($ average $=0.080)$ & 22050 & 0.055 \\
\hline $1.25 \star$ baseline $($ average $=0.133)$ & 160252 & 0.326 \\
\hline Threshold value $\$: 0.66{ }^{\star}$ baseline (average $\left.=0.070\right)$ & & \\
\hline \multicolumn{3}{|c|}{ Probability of a successful quit at six months for those attempting with NRT (baseline average $0.106 \mathrm{R}, 0.106$ OTC) } \\
\hline $\begin{array}{l}1.2 \star \text { baseline in } \mathrm{R} \text { scenario (average }=0.127 \text { ) and, } 0.8 \\
\star \text { baseline in OTC scenario (average }=0.084 \text { ) }\end{array}$ & 13933 & 0.037 \\
\hline \multicolumn{3}{|c|}{ Probability of a successful quit at six months for those attempting without NRT (baseline average $=0.049$ ) $\ddagger$} \\
\hline $0.8{ }^{\star}$ baseline (average $\left.=0.039\right)$ & 106265 & 0.235 \\
\hline $1.2 \star$ baseline $($ average $=0.059)$ & 76037 & 0.160 \\
\hline $2.0 \star$ baseline $($ average $=0.098)$ & 15581 & 0.040 \\
\hline \multirow{2}{*}{\multicolumn{3}{|c|}{$\begin{array}{l}\text { Threshold value } §: 2.3 \text {; }{ }^{\star} \text { baseline (average }=0.113 \text { ) } \\
\text { Probability of a successful quit at six months for fraction of those attempting without NRT but with non-pharmacological therapy } \\
\text { in OTC scenario (baseline average }=0.049) \ddagger\end{array}$}} \\
\hline & & \\
\hline $0.75 \star$ baseline $($ average $=0.037)$ & 32382 & 0.115 \\
\hline $0 \star$ baseline (average $=0$ ) & $(143924)$ & $(0.150)$ \\
\hline
\end{tabular}

NRT $=$ nicotine replacement therapy; OTC $=$ over the counter, $\mathrm{R}=$ prescription . ${ }^{\star}$ Changes in parameters noted as a multiplier; ${ }^{\star}$ baseline represents the values of the parameter across age and sex strata multiplied
by the number to achieve the result listed.

tMeasured in average years of life gained for an individual smoker.

$\ddagger$ The weighted average is the average of the values across age and sex strata adjusted to the American adult smoking population. These numbers are provided for reader reference; the analyses were performed using adjustment of each of the strata by the multiplier listed.

\The threshold value is the value of the parameter at which the life expectancy is equal in both the $\mathrm{R}$ and the OTC scenarios.

number of quitters in this scenario compared with the prescription scenario (table 2). For the original cohort of 47 million smokers, this gap between the smoking attributable mortality in the non-prescription setting and the prescription setting would continue to widen for approximately 30 years.

\section{SENSITIVITY ANALYSES}

Results of the sensitivity analyses demonstrated that the model results were robust for a wide range of changes in the baseline parameters (table 4 ). The results were most sensitive to changes in the parameter values of the relative chance of making a quit attempt by any method, and the relative probabilities of a successful quit at six months for the OTC and $\mathrm{R}$ scenarios. If, for example, the smokers are $10 \%$ more likely to attempt to quit by any method in the OTC scenario compared with the $\mathrm{R} x$ scenario, then the gain in number of quits at six months for the OTC scenario increases by $56 \%$ over baseline, and the gain in life expectancy for the OTC scenario increases by $43 \%$. Conversely, if either the chance of a successful quit at six months is either twice what we predict for the $\mathrm{R}$ scenario, or a half of what we predict for the OTC scenario, then the R scenario has more quitters and a better life expectancy.

Threshold values from the sensitivity analyses are also shown in table 4 . Threshold values are the values of the model parameters at which there is no longer a life expectancy benefit for smokers in the non-prescription scenario compared with the prescription scenario. For example, if smokers were only $79 \%$ as likely (or less) to attempt to quit by any method in the OTC scenario compared with the R scenario, then the OTC scenario would not have a life expectancy advantage.

\section{Discussion}

Smoking is a major source of morbidity and mortality in the United States. Thus, policies that even modestly improve smoking cessation rates have the potential to yield large public health benefits. In this analysis, we show that 
making nicotine replacement therapy using transdermal patches and nicotine gum available over the counter rather than prescription-only would result in a large increase in the number of successful quitters each year, a reduction in smoking-attributable mortality, and an increase in the life expectancy of smokers. The gain in life expectancy for an average smoker in the over-the-counter setting is 0.196 years; in comparison, the gain in screening 40-year-old men and 40-year-old women for hypertension would be an increase in life expectancy of 0.03 years and 0.01 years, respectively. ${ }^{22}$

Sensitivity analyses demonstrate that the over-the-counter use has a relative benefit compared with prescription use under a wide variety of assumptions. Perhaps the area of greatest uncertainty within the analysis is the six-month effectiveness data for both prescription and non-prescription nicotine replacement therapy. Data are available on NRT-assisted quit rates $^{5}$; these represent primarily efficacy results of clinical trials. In contrast, the analyses in this model used data estimating effectiveness of nicotine replacement under the OTC scenario. Surveillance data suggest that effectiveness of prescription-only patch use may have a $40 \%$ lower six-month success rate than we use for the baseline model..$^{19}$ Potential quitters willing to use NRT as an over-the-counter medication may, on average, have fewer or less severe factors for relapse. ${ }^{23}$ In contrast, smokers who seek cessation services (including NRT) through healthcare providers may, on average, include people with a greater number or level of relapse risk factors. ${ }^{10}$ If the six-month cessation rate for prescription use nicotine therapy is lower than we have estimated, then the actual benefits would be greater than we have calculated. Even if the six-month cessation rates for non-prescription nicotine replacement therapy use are $20 \%$ worse than we have estimated, and that of the prescription nicotine replacement use $20 \%$ better than estimated, our model still predicts a small benefit for the nonprescription availability setting.

There are several caveats that should be considered when evaluating our results. First, there are no randomised clinical trial data linking NRT-based smoking cessation programmes to overall reduction in mortality. Next, we do not explicitly address the issue of adverse effects of nicotine replacement. Since the analysis only addresses mortality associated with smoking, we did not include adverse effects because death directly attributable to NRT therapy itself is an exceedingly rare event, and thus would not change the results of the analysis. Other adverse effects of nicotine replacement therapy-for example, skin irritation from the transdermal patch - tend to be transitory and produce little impact on overall health. Finally, we do not address the economic impact of making nicotine replacement available without prescription.

Overall, we have found that making nicotine replacement therapy available without prescription would result in substantial public health benefit. By implementing a policy to make nicotine patches and gum available as over-the-counter medications for smoking cessation, the number of current smokers would significantly decrease over time, and smokingattributable mortality would decline as well.

This study was funded by a grant from SmithKline Beecham. Dr Lawrence is supported in part by Contract DAMD 17-96C-6069, "Breast Cancer Support Contract," from the Department of the Army. Dr Fiore has done consulting and public speaking for the following pharmaceutical companies: SmithKline Beecham, Ciba-Geigy, McNeil, and GlaxoWellcome.

1 US Department of Health and Human Services. Reducing the health consequences of smoking: 25 years of progress. A report of the Surgeon General, 1989. Rockville, Maryland: report of the Surgeon General, 1989. Rockville, Maryland: Public Health Service, Centers for Disease Control, Office (CDC) 89-8411.)

2 US Department of Health and Human Services. The health benefits of smoking cessation. A report of the Surgeon General, 1990. Rockville, Maryland: Public Health Service, Centers for Disease Control, Office on Smoking and Health, 1990. (DHHS Publication No (CDC) 90-8416.)

3 Gallup G Jr, Newport F. Many Americans favor restrictions on smoking in public places. Gallup Poll Monthly 1990;298:19.

4 Cohen S, Lichtenstein E, Prochaska JO, et al. Debunking myths about self-quitting: evidence from 10 prospective studies of persons who attempt to quit smoking by themstudies of persons who attempt to quit
selves. Am Psychol 1989;44:1355-65.

5 Fiore MC, Smith SS, Jorenby DE, et al. The effectiveness of the nicotine patch for smoking cessation: a meta-analysis. ҒAMA 1994;271:1940-7.

6 Silagy C, Mant D, Fowler G, et al. Meta-analysis on efficacy of nicotine replacement therapies in smoking cessation. Lancet 1994;343:139-42.

7 Orleans CT, Resch N, Noll E, et al. Use of transdermal nicotine in a state-level prescription plan for the elderly-a first look at "real-world" patch users. fAMA 1994; 271:601-7.

8 Pierce JP, Gilpin E, Farkas AJ. Nicotine patch use in the general population: results from the 1993 California Tobacco Survey. 7 Natl Cancer Inst 1995;87:87-93.

9 Fiore MC, Novotny TE, Pierce JP, et al. Methods used to quit smoking in the United States-do cessation programs help? $\mathcal{F} A M A$ 1990;263:2760-5

10 Lichtenstein E, Hollis J. Patient referral to a smoking cessation program: who follows through? $f$ Fam Pract 1992;34:739-45.

11 Marion Merrell Dow, Inc. Nicoderm (Nicotine transdermal system) prescribing information. Kansas City, Missouri: Marion Merrell Dow, 1991

12 Fiore MC, Jorenby DE, Baker TB, et al. Tobacco dependence and the nicotine patch: clinical guidelines for effective use. FAMA 1992;268:2687-94. 13 Benowitz NL. Nicotine replacement therapy: what has been
accomplished - can we do better? Drugs 1993;45:157-70.

14 Shiffman S, Gitchell J, Pinney JM, et al. Public health benefit of over-the-counter nicotine medications. Tobacco Control 1997;6:306-10.

15 Sox HC, Blatt MA, Higgins MC, et al. Medical decision making. Boston, Massachusetts: Butterworths, 1988.

16 US Department of Commerce. Statistical abstract of the United States 1994, 114th ed. Washington, DC: Department of Commerce, 1994.

17 US Centers for Disease Control. Cigarette smoking among adults-United States, 1990. MMWR 1992;41:354-5, $361-2$.

18 US Centers for Disease Control. Cigarette smokingattributable mortality and years of potential life lostUnited States, 1990. MMWR 1993;42:645-9.

19 SmithKline Beecham, Marion Merrell Dow. Supplement to FDA application 20-165 for approval of Nicoderm $21 \mathrm{mg} /$ day, $14 \mathrm{mg} /$ day, $7 \mathrm{mg} /$ day. Pittsburgh, Pennsylvania: SmithKline Beecham; Kansas City, Missouri: Marion Merrell Dow.

20 Beck JR, Pauker SG. The Markov process in medical prognosis. Med Decision Making 1983;3:420-58.

21 Thun MJ, Day-Lally C, Myers DG, et al. Trends in tobacco smoking and mortality from cigarette use in Cancer
Prevention Studies I (1959-1965) and II (1982-1988). In: Changes in cigarette-related disease risks and their implications for prevention and control. Bethesda, Maryland: National for prevention and control. Bethesda, Maryland: National
Cancer Institute, 1997: chapter 4. (NCI Monograph No 8.)

22 Littenberg B, Garber AM, Sox HC. Screening for hypertension. Ann Intern Med 1990;112:192-202.

23 Killen JD, Fortmann SP, Kraemer HC, et al. Who will relapse? Symptoms of nicotine dependence predict long-term relapse after smoking cessation. 7 Consult Clin long-term relapse after smoking cessation. F Consult Clin Psychol 1992;60:797-801. Hughes JR, Gulliver SB, Health Psychol 1992;11:331-4.

24 Hughes JR, et al. Smoking cessation among self-quitters. Health Psychol 1992;11:331-4. 